\title{
ONE STEP BEFORE THE MARKET - the innovative Business Ph.D. Program of the Faculty of Business AND ECONOMICS OF THE UNIVERSity OF PÉCS KISPÁL-VITAI ZSUZSANNA ${ }^{1}$
}

\begin{abstract}
This article aims to portray the history and the current characteristics of the International Ph.D. program of Business Administration at the Faculty of Business and Economics at the University of Pécs. It presents the events that led to the creation of the program, the philosophy of the founders, the governing idea that still prevails and the academic structure. Innovation and continuous development were those core values besides academic excellence that drove the responsible management towards constant learning and improvement. The last section of the article gives some aspects of the challenges of the future.
\end{abstract}

\section{Antecedents}

The history of the International Ph.D. program of Business Administration is inextricably linked to two leading trends of higher education in the 20th and the 21st century. One trend is internationalization of higher education; the other is teaching innovation. Both had been instrumental in the development of the Ph.D. program taught in English at the Faculty of Business and Economics.

The Faculty of Business and Economics of the University of Pécs was first established as a filial of Karl Marx University Budapest in 1970 and became the second location in Hungary where students could study business and economics. The location, educational content and the timing decided about innovation even at the beginning. The Faculty had to offer programs that were different from the ones provided in Budapest, so the founders created a teaching model that was concentrating on the needs of the companies, and not on macroeconomic analysis. Innovation was a keyword at the beginning, and the idea became a governing approach of the Faculty's leaders. After the transition, the pressing need to provide an education that was suitable to answer the challenges of the changing economy drove the Faculty towards a fast-paced internationalization. The first years of transition opened up a wide range of possibilities in establishing international relations. By 1996 the Faculty had well-operating contacts both in Europe and in the USA. Via the staff and student exchanges, these operational contacts provided information and possibilities for the Faculty to become more than a rural business school serving only the needs of the local business community. The needs of the Hungarian businesses also significantly changed during these years the incoming multinational companies needed staff with up-to-date business knowledge and good language skills.

In 1996 the Faculty started an English language Bachelor program and in 1999 the continuation of this program at the Masters level. The specialty of these is that they offer not just a Hungarian but also a British degree one provided by Middlesex University London. These had

\footnotetext{
${ }^{1}$ egyetemi docens, Közgazdaságtudományi Kar, Pécsi Tudományegyetem DOI: $10.14267 /$ RETP2019.04.10
} 
been continuously carried on with considerable success ever since their start and are still serving both the Hungarian and the international business communities' need of well-educated graduates. These programs were milestones on the road that led to the English language Ph.D. program.

The development of the international Ph.D. program started on the initiatives of participating in the global higher education arena and was helped by the favorable situation of the acceleration of globalization. At the beginning of the nineties, several international exchange programs were already in place in Western Europe and the USA. In Europe, the Erasmus exchange program started in 1987 [Jones, 2017], in the USA the Fulbright Scholar program was established even earlier in 1946 [Fulbright, 2019]. After 1990 the European Commission initiated the TEMPUS program for inclusion of Central-Eastern European countries into the European higher education field [Hagan, 2016]. The Faculty of Business and Economics actively participated in these programs and still has a high level of international activity. The Faculty dynamically utilized the benefits that arose with internationalization: the free flow of knowledge, the possibilities of participating in international research groups, students and lecturer exchange, the opportunity of having access to high-level educational infrastructure. First, the physical resources were modernized, at the same time, considerable care was taken to get access to the fast developing electronic resources. A conscious human resource development strategy enabled lecturers to learn the language of international education - English. (Today one important condition of lecturer recruitment is language knowledge.) Together with energetic resource development an active marketing approach towards the higher education market soon disclosed a market niche that was unrecognized by other tertiary education providers: the international student, who needs Ph.D. level education but cannot take an extended leave from work, or their country.

\section{Program Design - CURRICUlum AND Delivery}

Aims guide program design. In the case of the IPh.D. program, these were informed by the already existing international experience and the quality requirements of the school. The principal objective of this program was to educate international students to become proficient researchers with specific skills in a way that is unique to the Faculty of Business and Economics. When comparing Ph.D. programs most offer very similar study paths that lead to a pure research degree. The Faculty had to offer a unique selling proposition to compete in the highly saturated international business Ph.D. program market. This unique offer appeared both in program content and delivery.

At the Ph.D. level, it would seem natural to concentrate on the "create" - the highest level of Bloom's taxonomy [Armstrong, 2019]. In an international program where all participants are coming from different cultures, and not just students but lecturers are diverse, this approach would not be operational. In defining curriculum content, all steps were considered to synchronize students' knowledge to the level where they could begin their research with confidence. Student diversity was not only a disadvantage in the years it became a positive force that enriched the classroom experience. The differences in how students addressed professional issues, how they solved problems and interacted with each other and the lecturers became one of the main appeals of the program both for lecturers and the students. 
Figure 1. Bloom's taxonomy

\section{Bloom's Taxonomy}

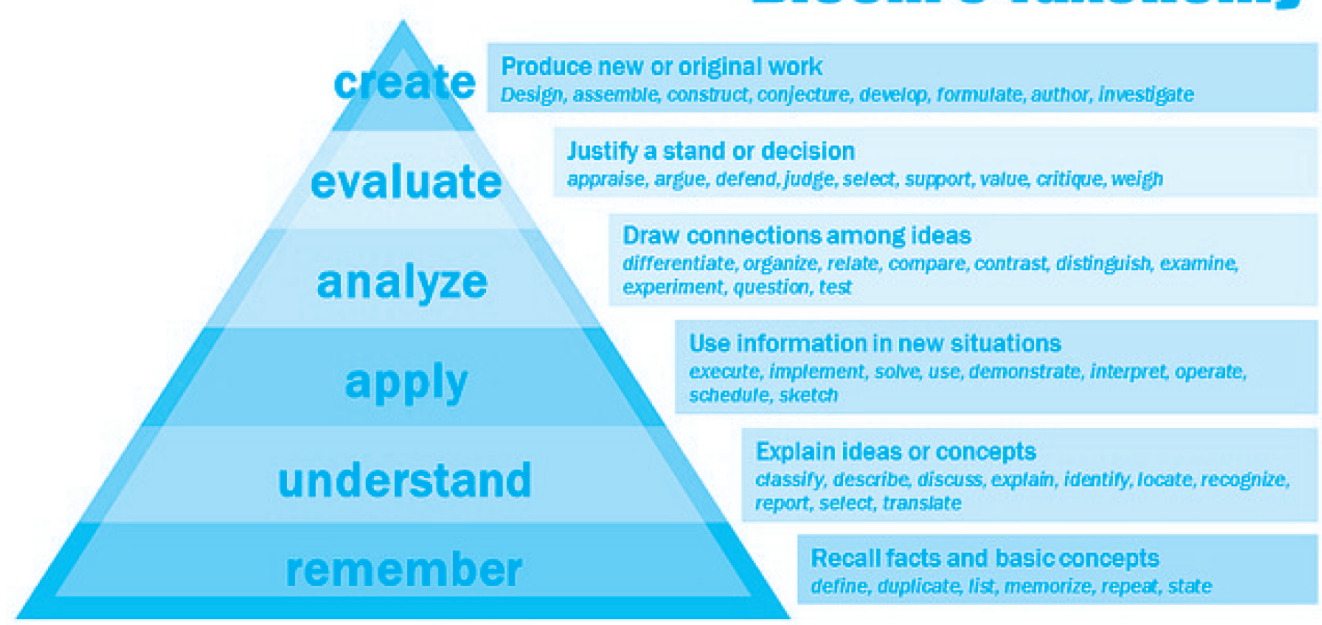

(9) (0) Vanderbilit University Center for Teaching:

Source: Armstrong, 2019. Vanderbilt University, Center for Teaching

In skills development, the program team concentrated first and foremost on discipline-specific skills, on acquiring research skills via coursework, but staff also emphasizes self-management and personal effectiveness. Skills training is built into the structure of the program, instead of formal training, it is taught in specific courses, such as effective communication in Organizational Behavior and Management subjects. Effective time management is enhanced by the quality assurance points, the milestones to be achieved, such as the proposal defense and the complex exam at the end of the second year, or the regular meetings with the supervisors. The Faculty consciously encourages conference participation and welcomes the IPh.D. students to the local conferences to help them in networking and assisting them in possible research collaborations and group work. [(Blickley et al. 2012., Winterton, Delamare - Le Deist, and Stringfellow (2006). Ph.D. Transferable skills...2019]

The first two semesters are intended to refresh and retrain students in the core functional areas of business: management, marketing, finance, operations where lecturers provide the founding Ph.D. level information for further studies. Crucial subjects in the compulsory design are those that prepare students for research; Principles of Business Research, Quantitative Methods, Statistics, Econometrics. Students have to prepare their research proposal by the end of the second year, which is evaluated by a committee of experts in the field. Besides preparing a research proposal documentation, students also have to defend their proposal before the evaluation committee and an audience. The proposal defense is public and accessible for all those who are interested in participating.

There are elective subjects in the program in the core disciplines; students have to choose from them. In addition to immersion in a field, these provide a possibility of broadening student horizons and impart current information about these more specific fields of research. 


\section{Delivery}

In the design of the international Ph.D. program besides internationalization, the other decisive factor was how program content should be delivered. Although the participants in Ph.D. courses are not always the typical "young" that is under 30 students, even the more mature generation needs a more interactive and more student-centered education. In studies leading to a Ph.D. degree personal tutoring is imperative, but providers cannot neglect transferable skills development. [Blickley et al. (2012., Winterton, Delamare - Le Deist, and Stringfellow, 2006. Ph.D. Transferable skills...2019] In 2001 at the start of the program, there were few Internetbased interactions between students and lecturers, the concept of blended learning was starting to get a foothold in higher education in Hungary. The needs of the students guided program design, and the rapidly developing Internet connections helped in the creation of specific subjects. The program design combines the American and European style Ph.D. programs [IPhD Program...2019]. There are compulsory courses to complete like in the US and there is ample room for independent research as the number of subjects and the contact hours are less than in a typical full-time Ph.D. course. Students have to be physically on campus during the intensive part of teaching, but otherwise, they are free to fulfill the requirements of courses in their own country. Contact is maintained with lecturers and administration via the Internet. The program uses a mixture of face-to-face and distance education and the concept of blended learning, where text-based asynchronous Internet technology is combined with face-to-face learning. (Garrison, Kanuka, 2004) Besides using the Internet extensively, lecturers in the program use high-level case studies also adding to transferable skills development.

Teaching methods are based on a blend of constructivist and objectivist approaches to teaching and learning. The reason for this hybrid approach lies in the needs and characteristics of the students - the colorful and different educational and cultural background. There are some functional areas of business where the objectivist approach is inevitable, in mathematics oriented subjects. Here the lecturers will transmit what is accepted as reliable knowledge of the phenomena and students have to understand and assimilate what is taught and replicate the knowledge in their research. Mathematical and statistics methodology requires teacher-centered teaching and learning, and student acceptance and internalization of techniques. The "soft side" of business knowledge though is more amenable to the constructivist approach where the teacher introduces new ideas but provides support and guidance to students to interpret and create meaning from phenomena themselves. The process is also a learning process for the teacher. Acceptance of multiple realities is important, and the creation of knowledge is emphasized in the classroom. [Murphy, 1997.] Without listing all, some of the design principles of constructivism are present in for example case study analyses: the focus on realistic approaches to solving real-world problems, stressing conceptual interrelatedness, and providing multiple representations or perspectives on the content, learning controlled internally by the learner [Murphy, 1997]. Research in social sciences benefits from this approach as multiple acceptance and representation of reality can add to the creative approach to existing problems.

The used methods are very diverse, but they are uniform in that respect that all aim to support students' learning. The "traditional" content delivery is almost gone, if present, it is present only in part of the classes. The whole program is based on interactivity, committed engagement of the students, substantive work in preparation for classes. Methods include blended learning, 
case study usage, Internet-based exercises, but perhaps the most important from them is the special relationship between the personal tutor and the student. Research guidance starts with the first steps the student takes at the Faculty, and it is there till the student finishes studies. This includes the connection after the school-type of education when after two years, students embark on their research. One of the leading characteristics of this program is this partly distance learning approach where the research student and the tutor keep contacts via the Internet.

\section{QUALITY ASSURANCE}

By the quality management policy of the Faculty, the program aims to convey the highest level of the current state of the art knowledge in the field of business. This is ensured by several policies, such as the continuous improvement of the physical and digital resources of teaching and learning, improvement of the library and the digital infrastructure, and the constant human resource development. Lecturers are supported in their research, and they are encouraged to participate in international research networks and conferences. Currently, three members of the Hungarian Academy of Sciences teach in the program. The IPh.D. program realizes one the Faculty's quality management aims by being a "borderless program" the delivery and the maintenance is not constrained, and is sustained in a considerable part via electronic means [Schepp, 2018]. Due to sustainable international relations, students enjoy having an international teaching team, among them world-class professors who regularly participate in education. This way diversity of professional views is secured, and students' skills in working with international researchers are also enhanced. A very important quality assurance point is the rigorous and strict system of requirements. These ensure that students stay on track and do not lose focus in the comparatively free learning environment.

\section{Challenges during the years}

Creation of a competitive English language Ph.D. carries with itself numerous obstacles to overcome. In program design, the main challenge was to harmonize the diverse backgrounds of the international students who come from all over the world, with different expectations and experiences. It needed careful human resource management to find those lecturers who were ready to face this obstacle and were committed to the high-level requirements of the program. Mistakes were inevitably committed, but the experience helped to overcome these. Succession planning is still in its infancy for the program, but the necessary policies now are in place.

One of the most significant obstacles were how the Faculty should advertise this program at a very saturated and highly competitive market. One "classic" marketing tool proved to be very effective: word of mouth marketing. The Internet again proved to be more of a potential than a marketing tool that is efficient. Still, the value of Internet advertising cannot be denied, but it is just one instrument among many others.

Students who study for a Ph.D. are by definition high maintenance people. They need elaborate guidance, effective administrative management, and constant care. It took years to find the well-operating administrative structure and the right people to operate them. The program has now one manager, whose responsibility is the smooth operational flow of studies, and also the responsibility of the professional care of the students, such as organizing events, exams, taking 
care of students' and lecturers' professional needs. One administrator deals with the mundane technical issues. Administration in education, especially in an international program, is like air, the less it is noticed, the better the operations. Years of experience proved the value of a welloperating administrative structure. Decision-making is informed by the administration, but it is centralized for speed and consistency.

In the management of students' study paths at the Faculty, the most important issue was how to keep up the motivation for their studies. Students who apply for the Ph.D. program have very specific desires and needs. Their behavior is guided by their ambition to obtain a prestigious degree from an influential institution. They come by their own accord, and their ambition cannot be denied. The challenge of this situation is to maintain this commendable ambition and to nurture the students' will to work towards the degree. Studies at this level are demanding, consume most of the daily activities of a person and setbacks sometimes are more numerous than successes. This situation is colored by the fact that the student works in a foreign country without the physical presence of family and friends. Keeping up work motivation in an alien environment with the possibility of lots of failures is still an issue in management. The support of the three fundamental human needs: autonomy, competence, and relatedness (Deci, Ryan, 2000) is the tool management uses to keep up work motivation. Students choose their research topic freely they may also change freely if they find they have come to a dead end. Personal tutoring together with class activities help in fighting culture shock when they arrive and frustration when they have to face obstacles. The inclusion of the students to Faculty conferences, workshops, research strengthens feelings of competence - these all ensure that they uphold their will towards completion of their studies. There are failures sometimes, not every student finishes the Ph.D. program, but the number of completions verifies the viability of this approach. From the beginning of the program in 2001, there are 31 students who obtained the Ph.D. degree. The number of students who enrolled from the beginning of the program is 109 .

\section{Challenges of the future}

According to the website Studyportals [Studyportals, 2019] in Business and Management, there are 595 Ph.D. programs in Europe, Asia, Africa, North America, and Oceania. These programs offer a bewildering range of study opportunities, some of them are even free of tuition fees. The IPh.D. program in Business Administration in Pécs has to survive in this saturated market, and the aim of the Faculty is not survival, but growth. Here the unique selling proposition of being flexible, innovative and professionally high ranking is not enough, because all these factors may be present in other countries in other better-known schools. The Faculty has to offer something else, and these specific resources are the experiences of transition and the unique location of the school. The Faculty is at the crossroads of East and West, the experiences of the still active lecturer generation of an exceptional phenomenon, the organically developed natural acceptance of diversity in people and views all provide a learning environment that is unmatched and does not exist anywhere else in the world. It needs aggressive marketing and conscious efforts on behalf of the Faculty.

The characteristics of the International Ph.D. program of the Faculty of Business and Economics of the University of Pécs qualify this educational arrangement into the category of disruptive innovation. According to Christensen et al. [2015] disruptive innovation occurs when a smaller 
business with a few resources can effectively challenge established incumbent businesses, that have more significance in the market. The smaller business entrant focuses on those customer segments that had been overlooked by the big businesses and serves their needs. The market segment the Faculty of Business and Economics serves is still not recognized by the important Ph.D. providers; those Master graduates who on the one hand are eager to study and for whom a Ph.D. title is important; should it be the reason of finding a more lucrative job or improving their academic career. On the other hand, these potential students cannot leave their jobs for the typical three years' duration of Ph.D. studies, but they can secure shorter leaves. Christensen et al. mention in their 2015 article the potentially disruptive innovation in higher education: online learning. The program combines online learning with the classic tradition of personal tutoring, enabling both students and lecturers to work together with the help of technology. Disruptive innovation's development is not fast it may take years to achieve substantial results, outcomes depend on the enabling technology [Christensen et al. 2015]. Outcomes are not independent of management handling the multiple demands the program poses towards the Faculty is an everyday task.

The future of the program is also influenced by the trends in the internationalization of higher education. One of these trends is the realization of the need for international development by the national governments [International Trends....] Some countries are considered very open and encouraging students' mobility such as Austria, Germany, Malaysia, China. Others are catching up, like France or Hungary for that matter. The Hungarian scholarship is a major attraction of studying in the country and enables students of less privileged countries to have access to international education. The scholarship students of the IPh.D. program are motivated, hardworking, their diversity is one of the most exhilarating factors in their teaching.

The future of international education will not always be the privilege of those universities that are now top-ranking on league tables. Universities in China and India are getting into these tables which will change the possibilities of students who desire international exposure. [University of Oxford, 2019.] It will also change the rules of the game for the traditional universities, competing with dynamic new entrants will pose a new challenge, as for the Faculty of Business and Economics as well. Pécs will not belong to the few exciting locations in Eastern-Europe, there will be more exciting places to go, and with the development of global mobility, students can choose for example Asian locations. The location will be less of a lure than before decisionmakers have to find other factors of competition as well. National governments realize that in competition quality assurance is a major decisive factor for students, so it has now grown in importance and governments invest in developing quality, for example in India and China [University of Oxford, 2019.]. Wiley educational services prepared an analysis of the graduate education market, where they found that program growth in distance education amounted to $98 \%$, whereas in "ground" that is brick and mortar education only 5\%. Competition among online programs grows by $19 \%$ per year. $38 \%$ of the programs in business are online. [Wiley, 2019] The data provide rather stiff challenges that need careful attention in the future.

One idea will not be changed though the mission of the program remains the same:

The mission of the International Ph.D. program of the Faculty of Business and Economics of the University of Pecs is to become a leading Ph.D. school in Central-Eastern Europe. We want to provide the highest level of research education together with careful attention to our student body. We believe in the power of knowledge in creating a better world. 


\section{REFERENCES:}

Armstrong, P. (2019). Bloom's taxonomy Vanderbilt University Center for Teaching Accessed at: https://cft.vanderbilt.edu/guides-sub-pages/blooms-taxonomy/ 08.02.2018.

Blickley, J.L., Deiner, K., Garbach, K., Lacher, I., Meek, M.H., Porensky, L.M., Wilkerson, M.L., Winford, E.M., Schwartz, M.W. (2012): Graduate Student's Guide to Necessary Skills for Nonacademic Conservation Careers, in: Conservation Biology, Volume 27, No. 1, pp. 24-34, doi: $10.1111 / j .1523-1739.2012 .01956 . x$

Christensen, C.M., Raynor, M., McDonald, R. (2015): What is Disruptive Innovation? in: Harvard Business Review, Vol. 93. Issue 12. pp. 44-53.

Deci, L.E., Ryan, R.M. (2000): The "What" and "Why" of Goal Pursuits: Human Needs and the Self-Determination of Behavior in: Psychological Inquiry, Vol. 11, No. 4, pp. 227-268

Fulbright (2019): History, accessed at: https://www.cies.org/history 27.01.2019.

Garrison, D.R., Kanuka, H. (2004): Blended learning: Uncovering its transformative potential in higher education, in: Internet and Higher Education Vol 7. pp. 95-105. doi:10.1016/j.iheduc.2004.02.001

Hagan, S. (2016): TEMPUS IV Programme, European Union, accessed at: https://eacea.ec.europa. eu/sites/eacea-site/files/2016_12_01-_ca_tempus_iv_study_internationalisation._docx. pdf 27.01.2019.

IPh.D. Program of Business Administration (2019) accessed at: http://ktk.pte.hu/en/education/ iphd-program-business-administration 27.01.2019.

Jones, H.C. (2017): Celebrating 30 years of the Erasmus programme, in: European Journal of Education, Vol. 52. Issue 4. pp. 558-562. https://doi.org/10.1111/ejed.12251

Murphy, E. (1997): Constructivist Learning Theory accessed at: http://www.ucs.mun. $\mathrm{ca} / \sim$ emurphy/stemnet/cle2b.html 27.01.2019.

Ph.D. Transferable Skills (2019) accessed at: https://grad.msu.edu/phdcareers/career-support/ skills 15.01.2019.

Schepp, Z. (2018): Quality Policy accessed at: http://ktk.pte.hu/sites/ktk.pte.hu/files/mellekletek/2018/10/quality_policy_faculty_of_business_and_economics.pdf\# overlaycontext=karunkrol/minosegiranyitas 27.01.2019.

Studyportals BV. (2019): PhDs in Business \& Management accessed at: https://www.phdportal. com/disciplines/23/business-management.html 25.01.2019.

University of Oxford: (2019): International Trends in Higher Education 2016-2017 accessed at: http://www.ox.ac.uk/sites/files/oxford/trends\%20in\%20globalisation_WEB.pdf 26.01.2019.

Wiley Education Services (2019): State of the Graduate Education Market, accessed at: https:// edservices.wiley.com/state-of-the-graduate-education-market/ 14.01.2019.

Winterton, J., Delamare Le-Deist, F., Stringfellow, E. (2006): Typology of knowledge, skills and competences: clarification of the concept and prototype. Cedefop Reference series; 64, Luxembourg Office for Official Publications of the European Communities 